\title{
Roles of Ephrin-As and Structured Activity in the Development of Functional Maps in the Superior Colliculus
}

\author{
Jianhua Cang, ${ }^{1}$ Lupeng Wang, ${ }^{1}$ Michael P. Stryker, ${ }^{2}$ and David A. Feldheim ${ }^{3}$ \\ ${ }^{1}$ Department of Neurobiology and Physiology, Northwestern University, Evanston, Illinois 60208, ${ }^{2}$ Department of Physiology, W. M. Keck Foundation \\ Center for Integrative Neuroscience, University of California, San Francisco, San Francisco, California 94143-0444, and ${ }^{3}$ Department of Molecular, Cell, and \\ Developmental Biology, University of California, Santa Cruz, Santa Cruz, California 95064
}

The orderly projections from retina to superior colliculus (SC) preserve a continuous retinotopic representation of the visual world. The development of retinocollicular maps depend on a combination of molecular guidance cues and patterned neural activity. Here, we characterize the functional retinocollicular maps in mice lacking the guidance molecules ephrin- $\mathrm{A} 2,-\mathrm{A} 3$, and - $\mathrm{A} 5$ and in mice deficient in both ephrin-As and structured spontaneous retinal activity, using a method of Fourier imaging of intrinsic signals. We find that the SC of ephrin-A2/A3/A5 triple knock-out mice contains functional maps that are disrupted selectively along the nasotemporal (azimuth) axis of the visual space. These maps are discontinuous, with patches of SC responding to topographically incorrect locations. The patches disappear in mice that are deficient in both ephrin-As and structured activity, resulting in a near-absence of azimuth map in the SC. These results indicate that ephrin-As guide the formation of functional topography in the SC, and patterned retinal activity clusters cells based on their correlated firing patterns. Comparison of the SC and visual cortical mapping defects in these mice suggests that although ephrin-As are required for mapping in both SC and visual cortex, ephrin-A-independent mapping mechanisms are more important in visual cortex than in the SC.

Key words: visual system; topography; axonal guidance; optical imaging; chemoaffinity; retinal waves

\section{Introduction}

Neuronal connections are often organized in a spatially precise manner to maintain the nearest neighbor relationships from an origin structure to its target, an arrangement called topographic mapping. A prominent model for studying how topographic maps are established during mammalian development is the projection of retinal ganglion cells (RGCs) to the superior colliculus (SC). Studies in the last several decades have indicated that the positional information of an RGC can be carried by at least two sources (McLaughlin and O'Leary, 2005).

First, as proposed by Sperry (1963) in the chemoaffinity hypothesis, a graded distribution of guidance cues in the RGC axons and SC cells can guide map formation by matching the two molecular gradients. The EphA family of receptor tyrosine kinases and their membrane-bound ligands, ephrin-As, have been shown to act as positional labels (Flanagan, 2006). EphAs/ephrin-As are expressed in countergradients along the nasotemporal (NT) axis of the retina and along the anterior-postrior axis of the SC (Cheng and Flanagan, 1994; Flenniken et al., 1996; Marcus et al., 1996; Zhang et al., 1996). Genetic studies in mice have shown that

Received May 9, 2008; revised Aug. 15, 2008; accepted Sept. 10, 2008.

This work was supported by National Institutes of Health Grants EY018621 (J.C.), EY02874 (M.P.S.), and EY014689 (D.A.F.). We thank Dr. Xiaorong Liu for her help with genotyping. We also thank members of the Cang and Feldheim laboratories and Drs. Andy Huberman, Alex Koulakov, and Dmitry Tsigankov for comments and discussions.

Correspondence should be addressed to Jianhua Cang at the above address. E-mail: cang@northwestern.edu. D0I:10.1523/JNEUROSCI.2478-08.2008

Copyright $\odot 2008$ Society for Neuroscience $\quad$ 0270-6474/08/2811015-09\$15.00/0 they are required for the formation of topographic maps along this axis (Frisén et al., 1998; Feldheim et al., 2000, 2004; Rashid et al., 2005; Pfeiffenberger et al., 2006).

The positional information of RGCs can also be carried by structured neural activity where neighboring cells are more correlated in their firing patterns (Willshaw and von der Malsburg, 1976; Montague et al., 1991). Indeed, correlated bursts of spontaneous activity propagate as waves across the retina during early development when the retinocollicular map is being established (Wong, 1999). When the precise structures of retinal waves are disrupted genetically or pharmacologically, the retinotopic maps in SC become less precise (McLaughlin et al., 2003; Cang et al., 2005b; Chandrasekaran et al., 2005; Mrsic-Flogel et al., 2005).

Together, these studies support a model in which guidance molecules guide RGC axons to form a rough map and patterned neural activity refines the map by clustering correlated inputs (Cline, 2003; Torborg and Feller, 2005). Indeed, computational studies combining these two factors could simulate the phenotypes of disrupted retinocollicular projections seen in mice where EphA/ephrin-As expression levels or activity patterns are manipulated genetically (Yates et al., 2004; Tsigankov and Koulakov, 2006). These models also make predictions of the entire structures of retinotopic maps in these mice. However, because experimental studies of retinocollicular mapping have primarily depended on anatomical tracing where only one or two injections can be made in each retina, the global structure of SC maps when EphA/ephrin-As interactions are genetically altered remains unknown. 
In this study, we apply a method of Fourier imaging of intrinsic signals (Kalatsky and Stryker, 2003) to visualize the functional maps in the mouse SC. By comparing the global structure of SC maps in wild-type (WT) mice, in mice lacking ephrin-A2, -A3 and -A5, and in mice deficient in both ephrin-As and structured activity, we reveal how guidance cues and neural activity contribute to the formation of retinotopic maps in SC.

\section{Materials and Methods}

Animals. Ephrin-A2/A3/A5 triple-mutant mice (Pfeiffenberger et al., 2006), and ephrin-A2A5-nAChR- $\beta 2$ combination knock-outs (KOs) were generated from crossing of each single mutant (Cutforth et al., 2003; Feldheim et al., 2000; Frisén et al., 1998; Xu et al., 1999). The animals were maintained in the animal facility at Northwestern University, University of California, San Francisco (UCSF), and University of California, Santa Cruz (UCSC), and were used in accordance with protocols approved by the Northwestern University, UCSF, and UCSC Institutional Animal Care and Use Committees. Ephrin-A2, -A3, -A5 and nicotinic acetylcholine receptor (nAChR)- $\beta 2$ mutations were genotyped as described previously (Frisén et al., 1998; Xu et al., 1999; Feldheim et al., 2000; Cutforth et al., 2003). WT mice from the C57BL/6 strain (Charles River Laboratories) were used as additional controls.

Functional optical imaging. To image retinotopic maps in the superior colliculus, adult mice (2-6 months old) were anesthetized with urethane $(1.2-1.3 \mathrm{~g} / \mathrm{kg}$ in $10 \%$ saline solution, i.p.) and supplemented by chlorprothixene $(0.2 \mathrm{mg} / \mathrm{mouse}$, i.m. $)$. Atropine $(0.3 \mathrm{mg} / \mathrm{kg})$ and dexamethasone $(2 \mathrm{mg} / \mathrm{kg})$ were injected subcutaneously. A tracheotomy was performed and a craniotomy was made in the left hemisphere. The overlying cortex was then aspirated, thereby exposing the SC.

Optical images of intrinsic signal were obtained at the wavelength of $610 \mathrm{~nm}$ illumination using a Dalsa 1M30 or 1P30 CCD camera controlled by custom software (Kalatsky and Stryker, 2003). After acquisition of a surface image, the camera was focused $400-500 \mu \mathrm{m}$ below the surface. Intrinsic signal images were acquired at the rate of 7.5 frames per second and stored as $512 \times 512$ pixel images. A high-refresh-rate monitor (Nokia $445 \mathrm{X}$ at $120 \mathrm{~Hz}$, or Viewsonic P225f at $100 \mathrm{~Hz}$ ) was placed $25 \mathrm{~cm}$ away from the animal. Drifting thin bars $\left(2^{\circ}\right.$ wide and full-screen long) were generated by a Matrox G450 board (Matrox Graphics) and displayed on the monitor. The spatial frequency of the drifting bar was $1 \mathrm{cycle} / 100^{\circ}$, and the temporal frequency was 1 cycle $/ 8 \mathrm{~s}$. Animals were presented with thin bars drifting along dorsoventral (DV) or NT axis (5-10 min for each direction) to stimulate the constant lines of elevation or azimuth, respectively. By extracting the optical signal at the stimulus frequency, we computed response magnitudes and timing in reference to the stimulus cycle, which can then be converted to the location of visual field. The absolute phase maps were then calculated by the method of "phase reversal" (Kalatsky and Stryker, 2003). The $0^{\circ}$ phase indicates the midline of the monitor, both horizontally and vertically. In addition, spatially restricted stimuli were used to assay azimuth map. Short horizontal bars of 10 or $20^{\circ}$ long and $2^{\circ}$ wide drifted vertically along different azimuthal positions on the monitor. Retinotopic maps in response to these stimuli were obtained using the same method as those using full-screen bars.

Analysis of retinotopic maps. We calculated several parameters to quantify retinotopic maps in the mouse SC. First, we determined the amplitude of peak response and the response area within $40 \%$ of the peak amplitude. We also determined the magnification factor of these maps by plotting the phase values along the $0^{\circ}$ contour line of their orthogonal map. We then calculated the distance between the two points along the line that had phase values of -20 and $20^{\circ}$, respectively. The magnification factor, in degrees per millimeter, is then the ratio of phase difference ( $40^{\circ}$ in this case) and the distance. For WT maps (Table 1), we calculated phase scatter of the 10,000 pixels $\left(0.80 \mathrm{~mm}^{2}\right.$ of SC surface) that had the greatest response magnitude. For each of these pixels, we calculated the difference between its phase value and the mean phase value of its surrounding 25 pixels (including itself). For maps of high quality, the phase differences are quite small because of smooth phase progression. The SD of the phase difference is then used as an index of map quality. To compare map quality of different genotypes (see Fig. 6), because the azimuth maps were weak and variable in the mutants, we used the 10,000 pixels having the greatest response in the elevations maps as templates to analyze both elevation and azimuth maps.

Modeling of retinotopic map formation in the superior colliculus. We followed the modeling studies of (Tsigankov and Koulakov, 2006) to simulate map formation in the SC. Briefly, the SC is represented by an N by $N$ matrix $(N=100)$, which is the termination sites for the RGC axons. The initial map is random, and then on each step of the optimization procedure, we choose two RGC axons in SC randomly and exchange them with the probability $p=1 /[1+\exp (\Delta E)]$, where $\Delta E$ is the change in adhesive energy caused by the exchange. The formation of retinotopic map in SC depends on two components, graded chemical guidance cues $\left(\Delta E_{\text {chem }}\right)$ and activity dependent refinement $\left(\Delta E_{\text {act }}\right)$, in the following form: $\Delta E=\Delta E_{\text {chem }}+\Delta E_{\text {act }}$.

The contribution of chemical guidance cues is modeled by the following formula: $E_{\text {chem }}=\sum_{i} \alpha \times R_{\mathrm{A}}(i) \times L_{\mathrm{A}}\left({ }^{\prime} r\right)-\beta \times R_{\mathrm{B}}(i) \times L_{\mathrm{B}}\left({ }^{\prime} r\right)$, where $R_{\mathrm{A}}(i)$ represents the EphA receptor level of point (i) in retina, and $L_{\mathrm{A}}\left({ }^{\prime} r\right)$ represents ephrin-A ligand level in its target point in SC; $R_{\mathrm{B}}(i)$ and $L_{\mathrm{B}}\left({ }^{\prime} r\right)$ simulate levels of receptors and ligands that have graded expressions and are required for map formation along dorsoventral axis, for example, EphB and ephrin-B (Hindges et al., 2002; Mann et al., 2002); and $\alpha=$ $\beta=120$ describes strength of contributions ( $\alpha=0$ to simulate the removal of ephrin-As).

The expression levels of these components are simulated following the original model (Tsigankov and Koulakov, 2006): $R_{\mathrm{A}}(x)=\exp (-x / N)-$ $\exp (x / N-2)$ and $L_{\mathrm{A}}(x)=\exp (x / N-1)-\exp (-1-x / N)$, where $x=$ $1 \ldots N$ is the coordinate along the NT axis. $R_{\mathrm{B}}(y)=\exp (y / N-1)$ and $L_{\mathrm{B}}(y)=\exp (y / N-1)$, where $y$ is the DV coordinate.

The contribution of activity-dependent process is modeled as: $E_{\mathrm{act}}=$ $-\gamma / 2 \sum_{i j} C_{i j} U\left({ }^{\prime} r\right)$, where $\gamma=1$ is the strength parameter, $C_{i j}$ is the crosscorrelation of neuronal activity between two RGCs during retinal waves, and $U$ simulates the overlap between two SC cells. Here, we use $C_{i j}=$ $\exp (-r / R)$, where $r$ is the retinal distance between axons $i$ and $j, R=$ $0.11 \times N$, and $U\left({ }^{\prime} r\right)=\exp \left(-{ }^{\prime} r^{2} / 2 d^{2}\right)$, where ${ }^{\prime} r$ is the distance between two SC points and $d=3$.

\section{Results}

Functional retinotopic maps in the mouse superior colliculus revealed by Fourier optical imaging

Neighboring RGCs project their axons to neighboring SC neurons, thus preserving a continuous retinotopic representation of the visual world. To visualize the functional retinotopic maps in the SC, we applied a method of Fourier optical imaging of intrinsic signals that has been used to visualize the structure of visual cortical maps (Kalatsky and Stryker, 2003). In this method, drifting thin bars are presented on a video monitor placed $25 \mathrm{~cm}$ away from the anesthetized mouse, contralateral to the hemisphere being imaged (Fig. 1A). The bars drifted along the DV or NT axis to stimulate the constant lines of elevation or azimuth, respectively (Fig. $1 B, E$ ). By extracting the optical signal at the stimulus frequency, we computed the response magnitude and timing in reference to the stimulus cycle, which can then be converted to the location in visual field. This method offers great increase of spatial resolution and reduction of time over the conventional imaging method of episodic stimulation and acquisition (Schuett et al., 2002; Kalatsky and Stryker, 2003). We find that this method obtains high-quality maps of absolute retinotopy in the SC with 10-20 min of acquisition for each axis of the visual space (Fig. 1). Because the overlying visual cortex has been removed to expose SC in these experiments, the map obtained in this manner represents functional input from the retina. We find that the DV axis (elevation) of the visual space is mapped approximately along the medial-lateral (ML) axis of the SC, and the NT axis (azimuth) of the visual space along the anterior-posterior (AP) axis of the SC, with the map slightly tilted anterolaterally (Fig. 1). This is consis- 
B.

A.<smiles>CCOC1CC2CCC(C2)C1</smiles>

F.
C.
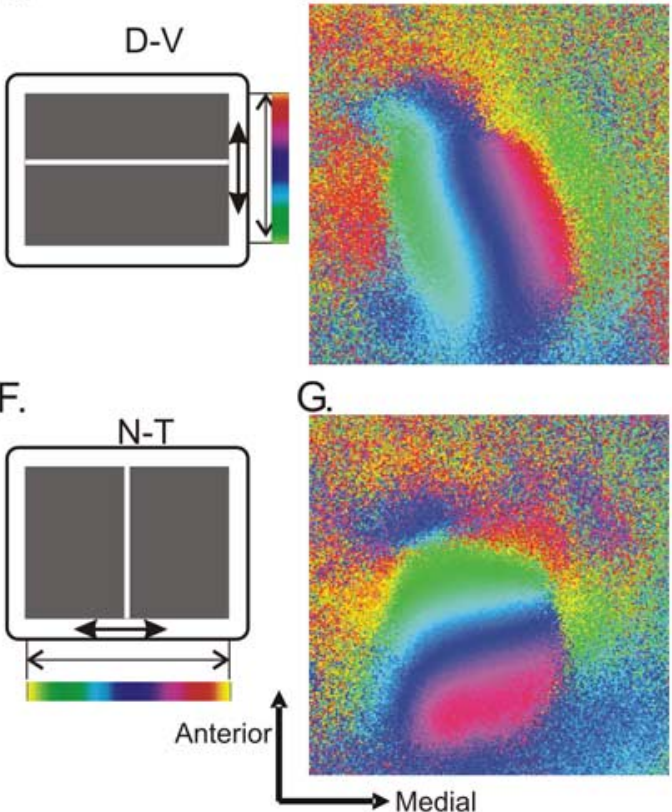

D.

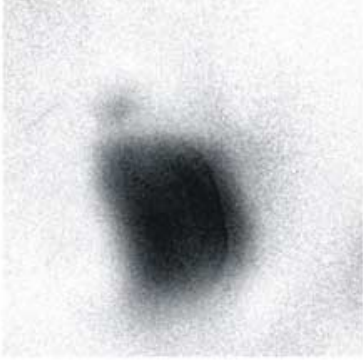

$\mathrm{H}$.

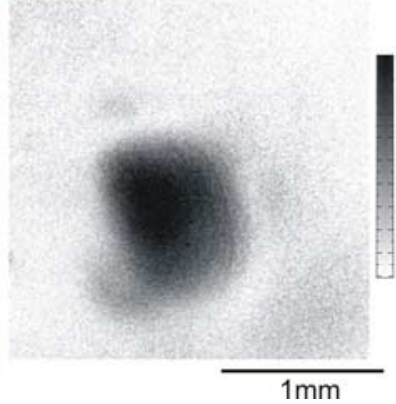

E.

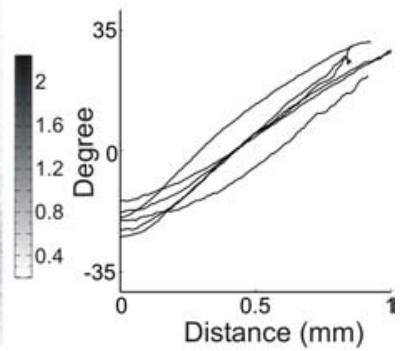

I.

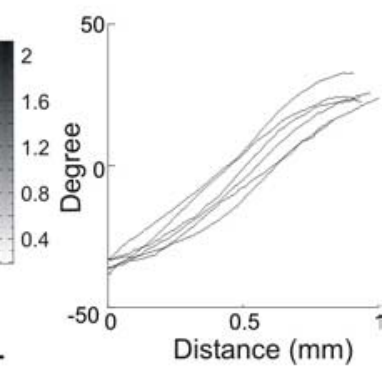

Figure 1. Functional retinotopic maps in the superior colliculus. $\boldsymbol{A}$, A stimulus monitor is placed $25 \mathrm{~cm}$ away from the anesthetized mouse, contralateral to the hemisphere being imaged. $\boldsymbol{B}-\boldsymbol{D}$, Elevation map in the SC of a WT mouse. Both retinotopy $(\boldsymbol{C}$ ) and response magnitude $(\boldsymbol{D})$ are shown. The color code used to represent positions of different elevation lines on the stimulus monitor is illustrated in $\boldsymbol{B}$, and the gray scale for response amplitude as fractional change in reflection $\times 10^{4}$ is shown to the right of $\boldsymbol{D}$. $\boldsymbol{E}$, Plot of visual field elevation as a function of collicular distance along the $0^{\circ}$ line in the mouse's azimuth map (G). $\boldsymbol{F}-\mathbf{I}$, Azimuth map in the same mouse.

A.
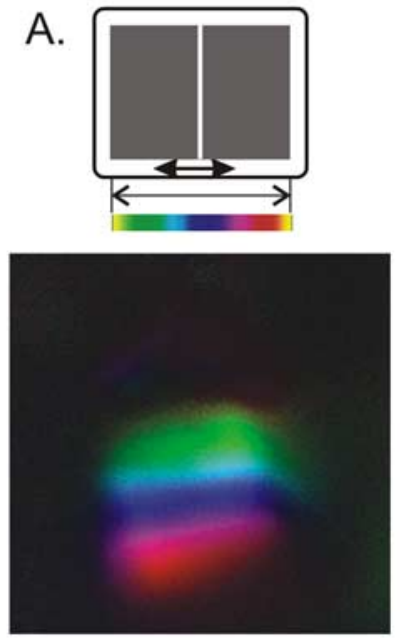

B.
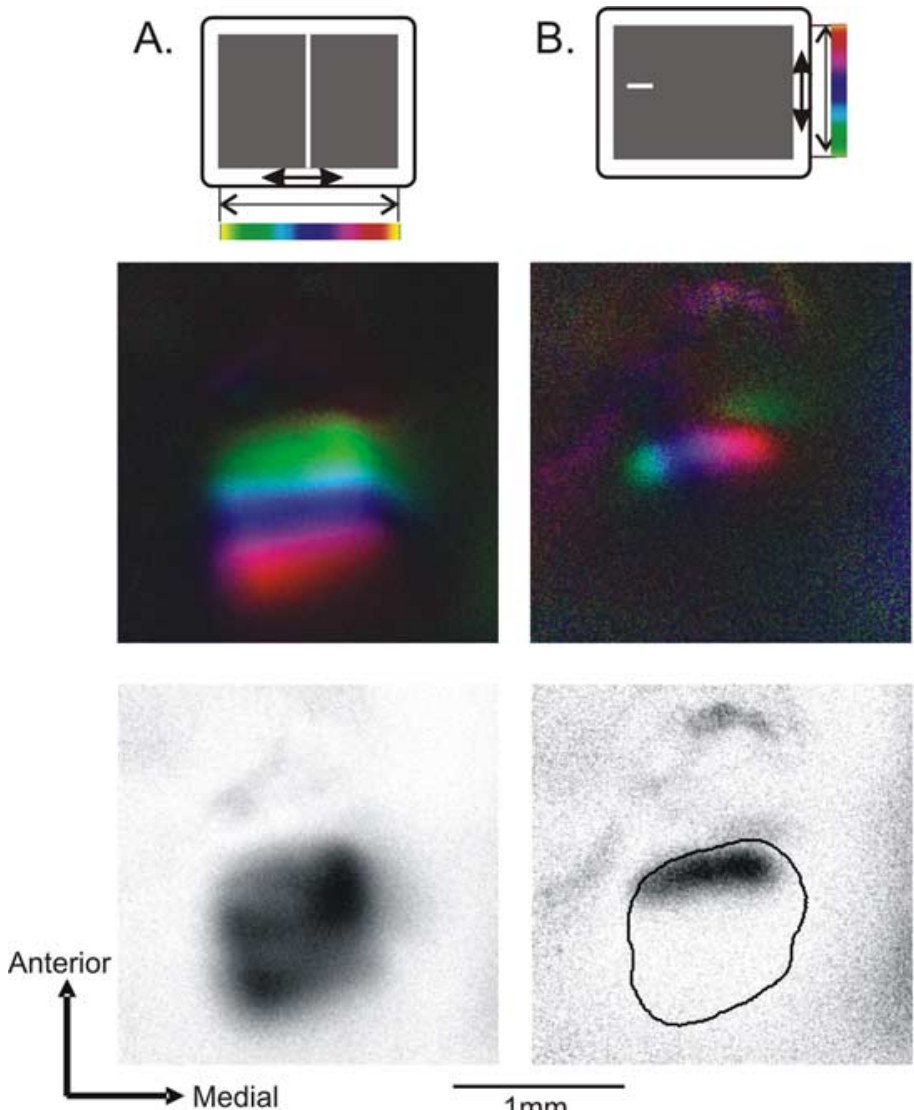

C.
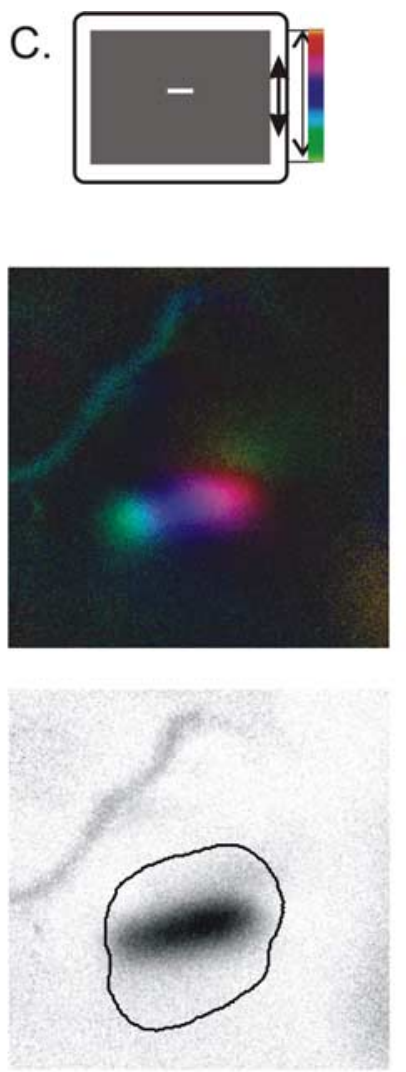

D.
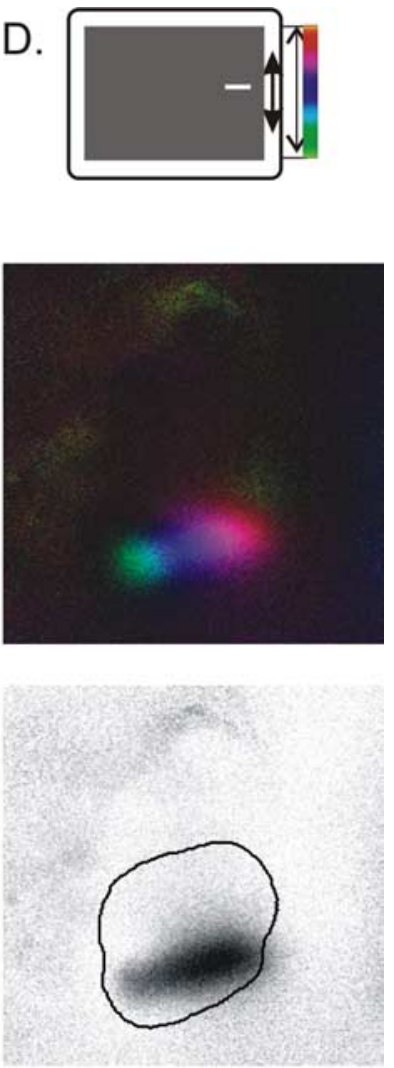

Figure 2. SC maps revealed by spatially restricted stimuli. $A$, Full screen azimuth map of a WT mouse. In the middle panel, the retinotopy is represented by color according to the color scales shown in the top panel, and the response magnitude is illustrated by lightness. The map of magnitude is shown separately in the bottom panel for clarity. $\boldsymbol{B}-\boldsymbol{D}$, Retinotopic maps and magnitude in response to spatially restricted stimuli as illustrated at top row. The black contour on each map of response magnitude circles the region activated by full screen stimulus (thresholded at a level of $40 \%$ of the peak response). 
tent with early electrophysiological findings (Dräger and Hubel, 1975, 1976).

Our imaging method also allows us to quantify several features of the retinocollicular map (Table 1). First, we determined the amplitude of peak response. As in the visual cortex, thin bars drifting along the DV axis evoked stronger response than those along the NT axis ( $3.2 \pm 0.5$ vs $2.3 \pm$ $0.3 \times 10^{-4}$ fractional change in reflection; $n=6)$. Second, the area of activation in both azimuth and elevation maps were similar in size $\left(1.03 \pm 0.08 \mathrm{~mm}^{2}\right.$ for elevation maps; $0.98 \pm 0.07 \mathrm{~mm}^{2}$ for azimuth; $n=6)$. Because this approach revealed the overall structure of the entire map in a single animal, we were able to determine the magnification factor of these maps by plotting the phase values along the $0^{\circ}$ contour line of their orthogonal maps (Fig. $1 E, I)$. The progression of visual space position is rather uniform and the magnification is anisotropic $(60.5 \pm 4.5 \% \mathrm{~mm}$ and $80.2 \pm 4.0^{\circ} / \mathrm{mm}$ for elevation and azimuth, respectively; $n=6$ ), consistent with the electrophysiological studies by Dräger and Hubel (1975, 1976) and retinotopic maps in the mouse visual cortex (Kalatsky and Stryker, 2003). However, our values of magnification factors are slightly greater than those obtained by Dräger and Hubel (1976) $(51 \% \mathrm{~mm}$ for the ML plane of the SC and $66 \% \mathrm{~mm}$ for the AP plane), presumably because of the difference in the analyses. We also calculated the angle between the two axes of the visual map in the SC $\left(79.3 \pm 2.6^{\circ} ; n=6\right)$. Finally, we analyzed quality of the maps by calculating "phase scatter" (Cang et al., 2005b) (for details, see Materials and Methods). The maps in wild type SC were judged to be of high quality, as the map scatter was quite small because of smooth phase progression $\left(1.14 \pm 0.21^{\circ}\right.$ and $1.39 \pm$ $0.15^{\circ}$ for elevation and azimuth, respectively; $n=6$ ). These descriptions and quantifications provide a basis for comparison with further studies combining mouse genetics and functional imaging to study the development of retinotopic maps in the superior colliculus.

To confirm the accuracy of the maps obtained by temporally encoded stimuli, we also obtained maps using spatially restricted stimuli (Fig. 2). In these experiments, we used short horizontal bars $\left(10^{\circ}\right)$ drifting vertically to define the area of activation in the SC in response to visual stimulation along different azimuth locations. As expected, when the center of the short bar was shifted horizontally in the visual field, the area of activation moved along the AP axis in the SC (Fig. $2 B-D$ ), following the azimuth map determined with full screen stimuli (Fig. 2A).

deg, Degree.

A.

B.

D.
Table 1. Quantification of SC maps in wild-type mice

\begin{tabular}{llllll}
\hline & Peak response $\left(\times 10^{-4}\right)$ & $\begin{array}{l}\text { Response } \\
\text { area }\left(\mathrm{mm}^{2}\right)\end{array}$ & $\begin{array}{l}\text { Map scatter } \\
(\mathrm{deg})\end{array}$ & $\begin{array}{l}\text { Magnification } \\
\text { factor }(\mathrm{deg} / \mathrm{mm})\end{array}$ & $\begin{array}{l}\text { Angle between } \\
\text { the two maps (deg) }\end{array}$ \\
\hline Elevation & $3.2 \pm 0.5$ & $1.03 \pm 0.08$ & $1.14 \pm 0.21$ & $60.5 \pm 4.5$ & \\
Azimuth & $2.3 \pm 0.3$ & $0.98 \pm 0.07$ & $1.39 \pm 0.15$ & $80.2 \pm 4.0$ & $79.3 \pm 2.6$ \\
\hline
\end{tabular}
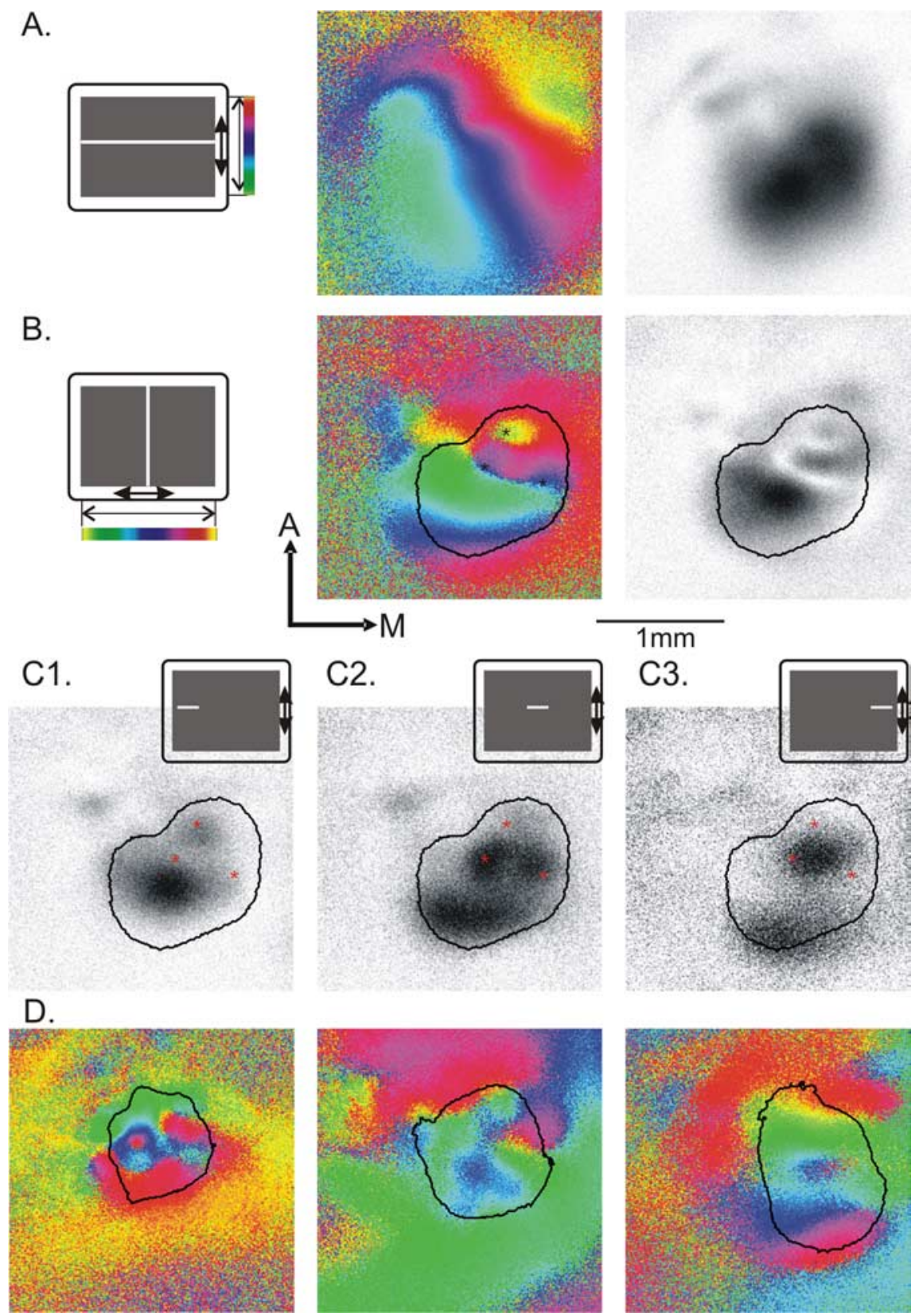

Figure 3. Retinotopic maps in the superior colliculus of ephrin-A2/A3/A5 triple K0s. $A$, Full screen elevation map of an ephrin-A triple KO. B, Full screen azimuth map of the same mouse. The black contour circles the region activated in the elevation map ( $40 \%$ of peak response). Note the discontinuous and patchy map. (1-C3, Maps of response magnitude to spatially restricted stimuli of the same mouse. Note the patchy patterns of activation, which correlates closely to the corresponding color in the full-screen azimuth map in $\boldsymbol{B}$. Asterisks mark the same threes points of $S \boldsymbol{C}$ in $\boldsymbol{B}$ and $\boldsymbol{C}$ to help the comparisons. $\boldsymbol{D}$, Additional examples of full-screen azimuth maps of ephrin-A triple KOs.

The above imaging procedures offer a rapid and reliable method to examine the complete structure of the SC retinotopic maps in a single mouse, and thus provide a functional correlate to focal retinal injections that have been traditionally used to trace the topography of retinocollicular projections. 

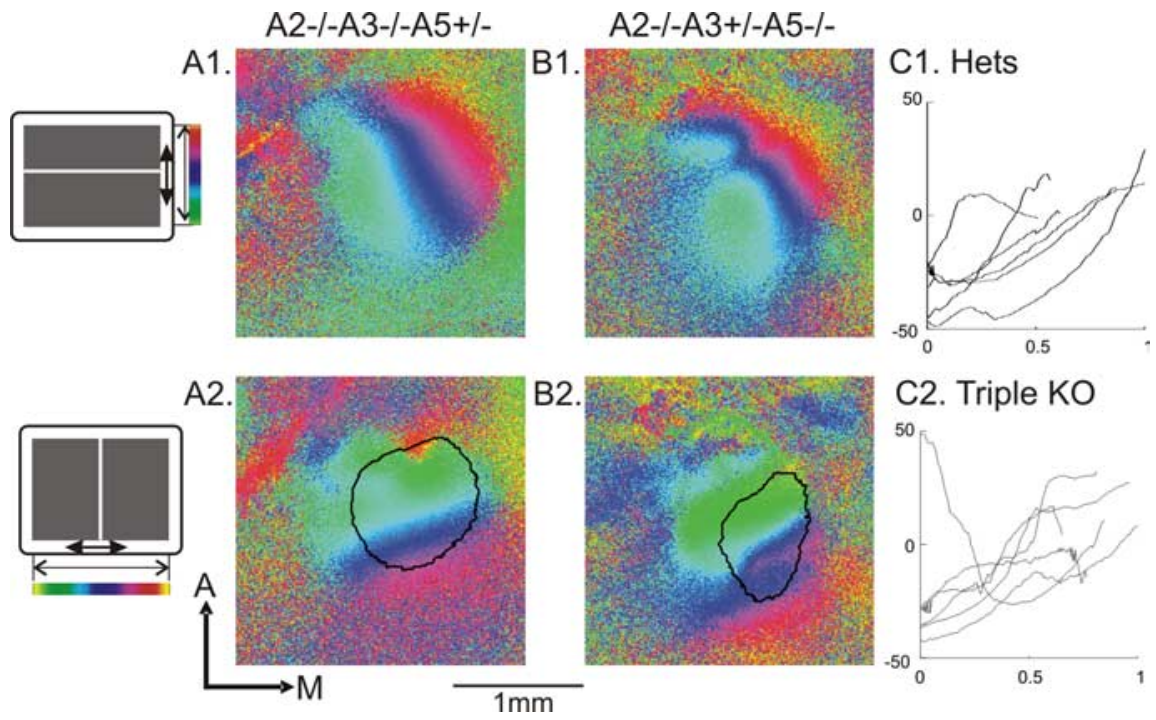

Figure 4. Retinotopic maps in the superior colliculus of ephrin-A mutants. $\boldsymbol{A 1}, \boldsymbol{A 2}$, Elevation (A1) and azimuth (A2) maps of an ephrin-A2 $2^{-1-} A 3^{-1-} A 5^{+1-}$ mouse. The black contour circles the region activated in the elevation map (40\% of peak response). B1, B2, Elevation (B1) and azimuth (B2) maps of an ephrin-A2 $2^{-1-} A 3^{+/-} A 5^{-1-}$ mouse. C1, C2, Plots of azimuthal location along $0^{\circ}$ elevation line of ephrin-A2A3A5 compound heterozygotes (C1) and triple KOs (C2).

that the formation of azimuth maps in the absence of ephrin-A guidance cues is mostly random. Interestingly, in most of the maps of the ephrin-TKOs, some patches appeared near their normal positions (Fig. 3, see green in more anterior SC and red in more posterior). This is consistent with anatomical studies of ephrin-A KOs where focal injections in the retina always resulted in one termination zone near its correct location and one to two aberrant clusters in the SC (Feldheim et al., 2000; Pfeiffenberger et al., 2006). The number of patches in the maps evoked by the small bars (Fig. 3C) is thus similar to the number of termination zones. Furthermore, in all TKOs imaged, nasal visual stimulation (activation of temporal axons) could activate areas more posterior in the SC than normal, whereas temporal stimulation could activate more anterior regions than normal (Fig. 3C,D), consistent with the tracing results in these ephrin-A TKOs (Pfeiffenberger et al., 2006).

We also imaged the SC maps in various

\section{Disruption of functional maps in the superior colliculus by deficiency in ephrin-As}

A number of studies have tested the role of ephrin-A2, -A3, and -A5 (the three ephrin-As predominantly expressed in the developing visual system) in retinocollicular map formation by tracing the projection pattern of a small number of RGCs in mutant mice. These experiments have shown that ephrin-As are necessary for topographic mapping of the retinocollicular projection in vivo. The ephrin-A5 mutants have the strongest single mutant phenotype, but the penetrance and severity of the mapping defects increases when ephrin-A2 and ephrin-A3 are combined with ephrin-A5 (Frisén et al., 1998; Feldheim et al., 2000; Pfeiffenberger et al., 2006).

To examine the overall structure of SC maps in ephrin-A mutants, and to determine whether the anatomically disrupted retinocollicular projections remain functional, we imaged the SC of mice lacking ephrin-A2, -A3, and -A5 [ephrin-A triple knockouts (TKOs) ] using the above described imaging paradigm. Using full-screen stimuli, we found that the functional azimuth maps in the SC of ephrin-A TKOs were discontinuous (Fig. 3B), whereas the positional progression in the elevation map was relatively normal (Fig. $3 A$ ). We further confirmed this result with spatially restricted stimuli. Instead of activating small bands of SC in the topographically correct locations seen in WT, short $\left(20^{\circ}\right)$ horizontal bars drifting along the DV axis evoked patches of responses in ephrin-A TKOs (Fig. 3C). The patchy patterns of activation matched very well with the azimuth maps determined with full-screen stimuli (Fig. $3 B, C$, compare regions marked with asterisks). For example, in the example shown in Figure 3, the regions responding most strongly to the short bars along the monitor midline (Fig. 3C2) had blue colors in the azimuth map (Fig. $3 B$ ), corresponding to the same area on the stimulus monitor. The same agreement was true for the other two positions (Fig. 3, compare $C 1$ with green color in $B, C 3$ with red $B$ ), thus confirming the reliability of our imaging methods and the disruption of azimuth maps in ephrin-A TKOs.

Importantly, the structures of the azimuth maps in ephrin-A TKOs varied greatly from mouse to mouse (Fig. 3D), suggesting heterozygous littermates of ephrin-A TKOs, including ephrin$A 2^{-/-} A 3^{-/-} A 5^{+/-}$and ephrin- $A 2^{-/-} A 3^{+/-} A 5^{-/-}$. Despite the deletion of most of the ephrin-As in the developing visual system, these mice had better positional progression of azimuth maps in their SCs (Fig. 4A,B) than the ephrin-A TKOs. We illustrated these observations by plotting the visual field position on the azimuth maps along $0^{\circ}$ contour lines of the elevation maps of the same mice. Unlike WT mice, where visual field progression was smooth and monotonic along the AP axis the SC (Fig. 1I), the retinotopic progression was severely disrupted in the ephrin-A TKOs, with discontinuities and fractures in many cases (Fig. 4C2). Retinotopic progression in heterozygous controls was abnormal but not nearly as disrupted, with correct global polarity and often monotonic progression (Fig. 4C1). These results suggest that the small amount of remaining ephrin-As, especially ephrin-A5, are able to guide a rough map along the azimuth axis, consistent with the idea that retinocollicular map formation is controlled by relative levels of EphA/ephrin-A signaling (Brown et al., 2000; Feldheim et al., 2000).

\section{Structured retinal activity clusters RGC inputs in the SC}

The patchiness of activated areas in response to azimuthally restricted stimuli in the ephrin-A TKOs (Fig. 3) indicate that large groups of neighboring RGCs can innervate neighboring areas in the SC, albeit regions that are topographically inappropriate. Previous anatomical and modeling studies suggest that the clustering of these projections could result from correlated neuronal activity among neighboring RGCs during development (Pfeiffenberger et al., 2006; Tsigankov and Koulakov, 2006). Here, we implemented the model proposed by Tsigankov and Koulakov (2006) to illustrate the above hypothesis. In this model, the formation of retinotopic map in SC depends on two components: graded chemical cues and activity-dependent refinement. The chemical cues along the NT axis of the map simulate the graded expression of EphA and ephrin-A in both retina and SC (for detailed descriptions, see Materials and Methods). The SC is represented by a $100 \times 100$ matrix to simulate the termination sites for RGC axons. The initially random map underwent a number 

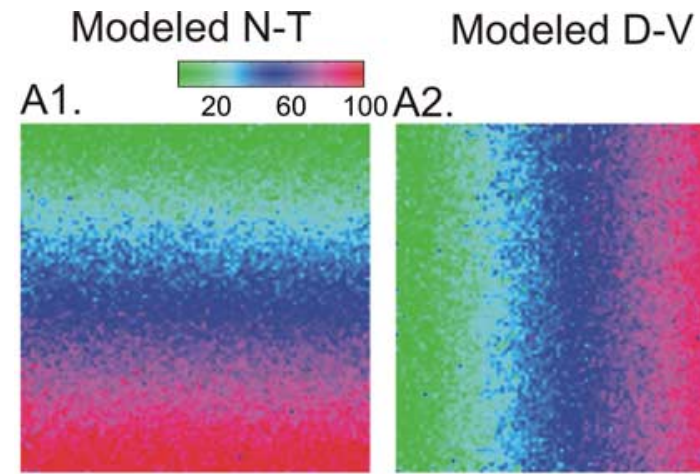

B1.

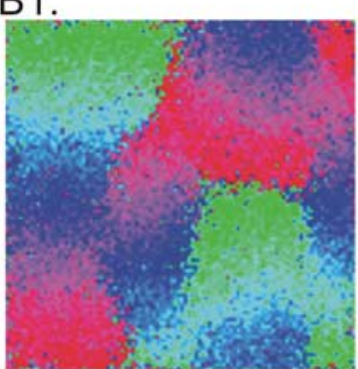

C1.
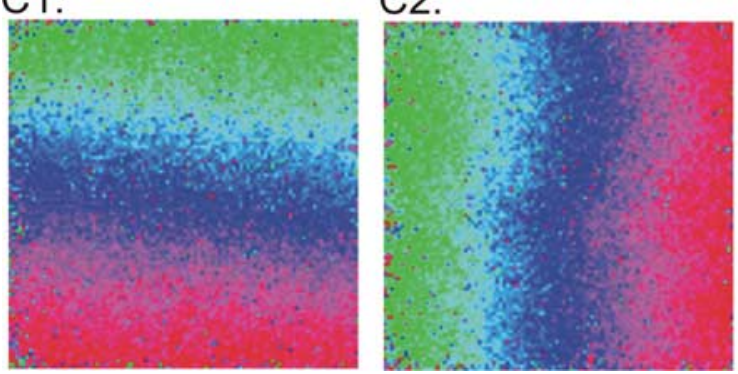

Figure 5. Modeling map formation in the presence and absence of ephrin-As. The SC is represented by a $100 \times 100$ matrix, which are the termination sites for RGC axons. The formation of retinotopic map in $\mathrm{SC}$ depends on two components: graded guidance cues and activitydependent refinement. $\boldsymbol{A} \mathbf{1}, \boldsymbol{A} \mathbf{2}$, Resulted maps with these two components, with the color codes of retinal positions shown at the top. $\boldsymbol{B} \mathbf{B} \mathbf{B}$, Removal of guidance cues along the azimuth axis results in discontinuous, patchy maps along this axis $(\boldsymbol{B} 1)$, while leaving the elevation axis (B2) mostly normal. C1, C2, Modeled maps in the absence of activity-dependent refinement process.

of optimization steps. In each step, we chose two RGC axons in the SC randomly and exchanged them with the probability $p=$ $1 /[1+\exp (\Delta E)]$, where $\Delta E$ was the change in adhesive energy caused by the exchange $\left(\Delta E=\Delta E_{\text {act }}+\Delta E_{\text {chem }}\right.$ ) (for details, see Materials and Methods). After $10^{6}$ steps, orderly organization of retinotopic maps appeared (Fig. $5 A$ ). When the interaction of guidance cues along the NT axis was removed in the model, the remaining activity-dependent mechanism resulted in patchy and random maps along this axis (Fig. 5B1), reminiscent of the functional maps we saw in the imaging experiments (Fig. 3 ).

It is thought that the activity-dependent positional information comes from correlated bursts of spontaneous activity that propagate as waves across the retina early in development (Galli and Maffei, 1988; Meister et al., 1991). The precise structures of retinal waves are disrupted in mice lacking the $\beta 2$ subunit of the nAChR (nAChR- $\left.\beta 2^{-/-}\right)$(Xu et al., 1999; Bansal et al., 2000). Several groups have shown that the retinocollicular maps in the $\beta 2^{-1-}$ mice are more scattered but of correct global polarity (McLaughlin et al., 2003; Cang et al., 2005b; Chandrasekaran et
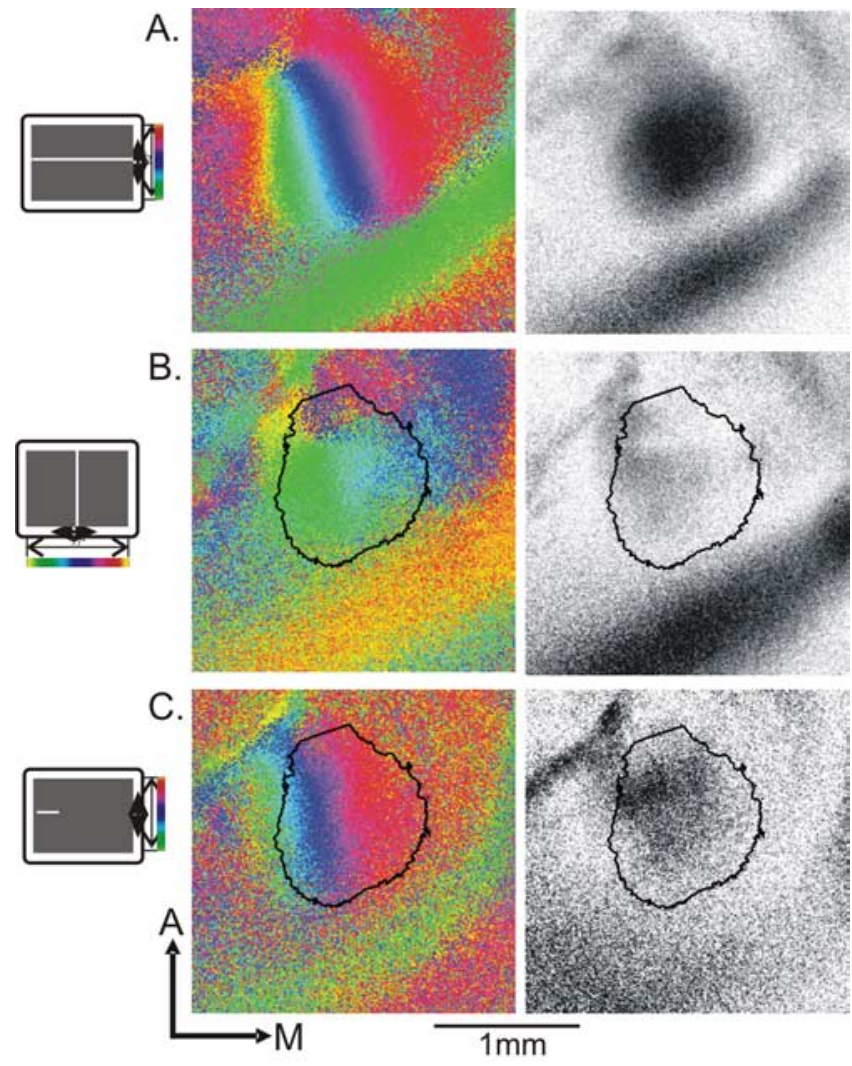

\section{Elevation}

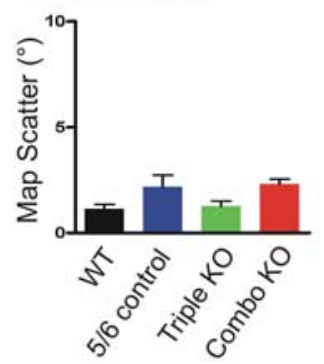

E. Azimuth

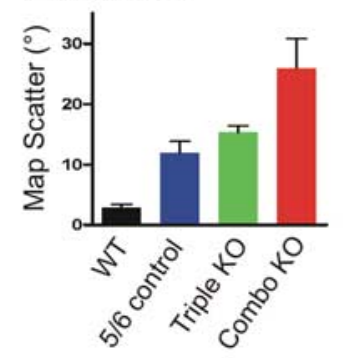

Figure 6. Retinotopic maps in the superior colliculus of ephrin-A2/A5- $\beta 2$ combination $\mathrm{KO}$. $A$, Elevation map of an ephrin-A2 $2^{-1-} A 5^{-1-} B 2^{-1-}$ mouse. Both maps of retinotopy and response magnitude are shown. $\boldsymbol{B}$, Azimuth map of the same mouse. The black contour circles the region activated in the elevation map ( $40 \%$ of peak response). Note the lack of retinotopic progression in the SC. C, Response to a spatially restricted stimulus, shown to the left. D, E, Map scatter of elevation $(\boldsymbol{D})$ and azimuth $(\boldsymbol{E})$ maps of different genotypes.

al., 2005; Mrsic-Flogel et al., 2005), similar to the modeled maps in the absence of activity-dependent process (Fig. $5 C$ ).

To study the functional consequence of disrupting early retinal waves in the ephrin-A-deficient mice, mice deficient for ephrin-As were crossed with $\beta 2^{-1-}$ mice to obtain ephrinA2A5- $\beta 2$ combination KOs (Pfeiffenberger et al., 2006; Cang et al., 2008). Because ephrin-A3 and $\beta 2$ are genetically linked, we are unable to create an ephrin-A2/A3/A5- $\beta 2$ quadruple $\mathrm{KO}$. In the ephrin-A2A5- $\beta 2$ combination KOs, the azimuth maps determined with full screen stimuli were very weak and lacked global topography (Fig. 6B), whereas elevation maps were of remarkably good quality (Fig. 6A). These observations were supported by our quantification of map scatter (Fig. $6 D, E$ ). The ephrinA2A5- $\beta 2$ combination KOs had huge scatters in their azimuth maps $\left(26.0 \pm 4.9^{\circ} ; n=6\right)$, significantly larger than those of ephrin-A TKOs $\left(15.3 \pm 1.1^{\circ} ; n=6 ; p<0.05\right)$. Finally, the severe disruption of the azimuth map was further confirmed by spatially 


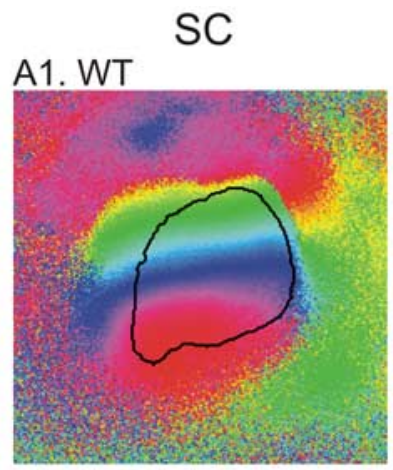

B1. ephrin-A TKO

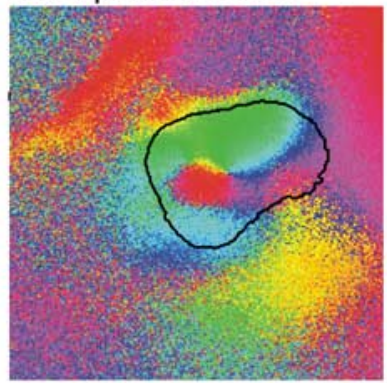

C1. ß2 KO

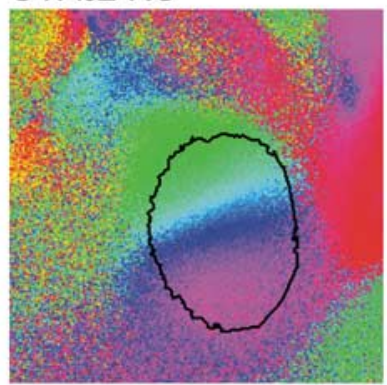

D1. Combination $\mathrm{KO}$

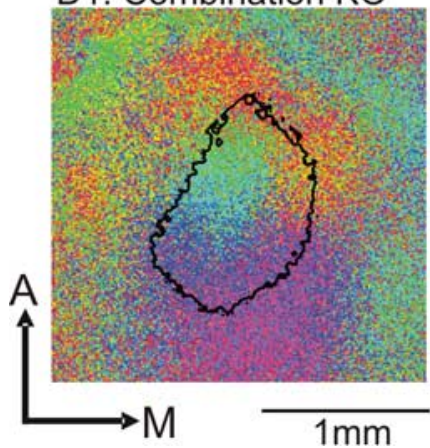

Visual Cortex

A2.

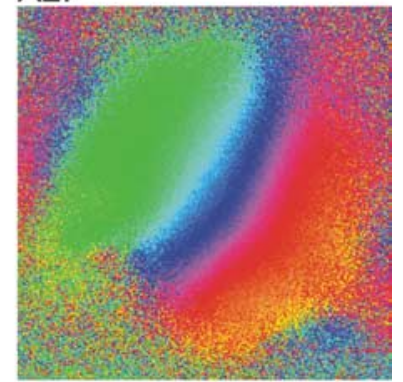

B2.

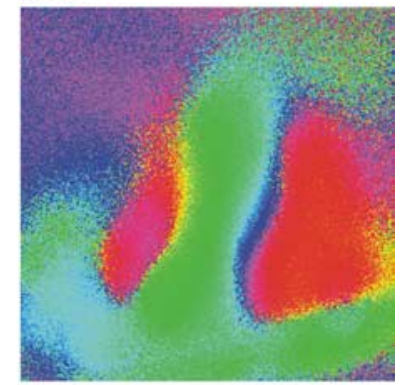

C2.

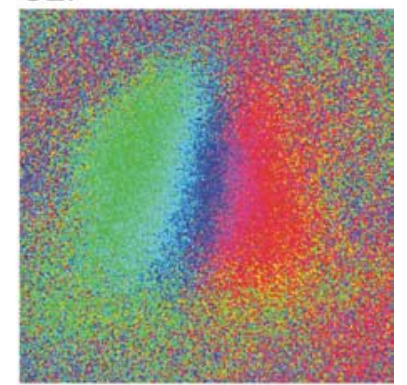

D2.

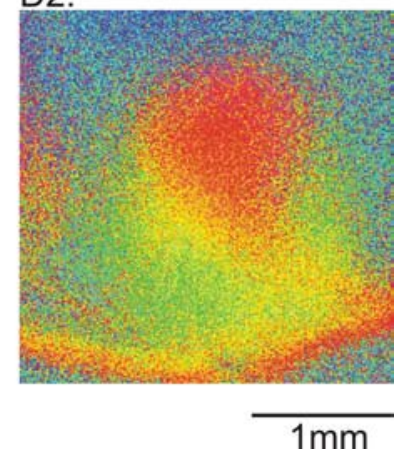

Figure 7. Comparison of azimuth maps in the superior colliculus and visual cortex. A1, A2, Azimuth maps in the SC (A1) and visual cortex (A2) of a WT mouse. The black contour circles the region activated in the elevation map (40\% of peak response). B1, B2, Azimuth maps of an ephrin-A2/A3/A5 triple K0. Note that the $S C \operatorname{map}(B 1)$ is patchy, and the V1 map (B2) is not, but blurred. C1-D2, Azimuth maps of a $\beta 2$ KO (C) and an ephrin-A2/A5- $\beta 2$ combination KO (D).

restricted stimuli, which resulted in weak, and very diffused activation in much of the SC (Fig. $6 C$ ). Therefore, our results indicate that the local patches of SC maps in the absence of ephrin-As (Fig. 3 ) are driven by $\beta 2$-dependent patterned activity during early retinal waves, and that the disruption of both ephrin-As and structured activity almost completely abolishes the azimuth map in the SC.

\section{Comparison of SC and cortical maps}

We have shown previously that ephrin-A TKOs have large anatomical defects in their geniculocortical projections, but the functional maps in primary visual cortex (V1) are not patchy as in the SC (Cang et al., 2005a). Instead, the V1 azimuth maps in the ephrin TKOs are blurry and compressed, but with normal global polarity. Here, we confirm this observation by imaging the visual maps in the SC and V1 in the same mouse (Fig. $7 B$ ). In addition, we have previously quantified map quality of visual maps in the $\beta 2 \mathrm{KOs}$ and found that their V1 maps are more scattered than SC maps (Cang et al., 2005b). Finally, when both ephrin-As and structured activity are disrupted, the topography along the NT axis is nearly abolished in both SC and V1 (Fig. 7D), while leaving their DV maps relatively normal (Cang et al., 2008) (Fig. 6).

Together, these comparisons indicate that, although both ephrin-A- and activity-dependent mechanisms are used to map visual projections, their relative contributions to form functional maps differ in the SC and V1.

\section{Discussion}

The orderly projections from retina to superior colliculus in mammals or to tectum in other vertebrates are a leading model for the study of axonal guidance and topographic map formation. Here, we have adapted a method of Fourier optical imaging of intrinsic signals to examine the functional retinotopic maps in the mouse SC. The overall structure of SC maps to full-screen stimuli and the areas activated by spatially restricted stimuli can be revealed rapidly and reliably. Using this method, we have studied the SC maps in mice lacking the molecular guidance cues ephrin-A2, - A3, and - A5, and in mice deficient in both ephrin-As and structured activity. Our experiments indicate that in the absence of ephrin-As, the functional SC maps are disrupted selectively along the azimuth axis of the visual space. These maps are discontinuous, with patches of SC responding to topographically incorrect locations. The patches disappear in mice that are deficient in both ephrin-As and structured activity, resulting in a near absence of azimuth map in the SC. Together, our experiments demonstrate that ephrin-As and structured activity account almost completely for the formation of azimuth maps in the SC, and that in the absence of ephrin-As, structured retinal activity is able to guide neighboring ganglion cells to form local clusters in the SC.

\section{Retinotopic map formation in superior colliculus}

How does a ganglion cell know its position in the retina and where to terminate in the SC? Studies have shown that EphAs and ephrin-As act as positional labels along the NT axis via their graded expressions in the retina and SC (Flanagan and Vanderhaeghen, 1998; McLaughlin and O'Leary, 2005). Axons of the temporal RGCs (that contain high EphA level) project to anterior SC (low ephrin-As) and nasal axons (low EphAs) project to posterior SC (high ephrin-A), consistent with the repulsive nature of EphA/ephrin-A interactions (Cheng et al., 1995; Drescher et al., 1995). Loss-of-function studies in mice have demonstrated that ephrin-As are required for retinocollicular mapping (Frisén et al., 1998; Feldheim et al., 2000; Pfeiffenberger et al., 2006). The most severe mapping errors are seen when all of ephrin-A2, -A3, and -A5 are removed from a mouse, suggesting that these family members act redundantly (Pfeiffenberger et al., 2006). Because these studies used only anatomical tracing of retinal projections, it remained unknown before our current study whether the aberrant terminations seen in ephrin-A mutants are functional. Here, we used an optical imaging method to show that the SC of the ephrin-A TKO does contain functional maps that are discon- 
tinuous and patchy, with that nasal visual stimulation can activate areas more posterior than normal, whereas temporal stimulation can activate more anterior regions.

The coarse map formed by molecular guidance cues is refined by neural activity-dependent mechanisms. During the first postnatal week, when the retinocollicular map is being established in mice (Godement et al., 1984; Simon and O'Leary, 1992), correlated bursts of spontaneous activity propagates as waves across the developing retina (Bansal et al., 2000; Demas et al., 2003), as in other mammals (Galli and Maffei, 1988; Meister et al., 1991; Warland et al., 2006). In activity-dependent mapping models, neurons with similar activity patterns are more likely to synapse on the same or adjacent target cells than are neurons with different activity patterns (Butts and Rokhsar, 2001; Debski and Cline, 2002). Indeed, when the precise structure of retinal waves is disrupted during this stage because of deletion of the $\beta 2$ subunit of nAChR (Bansal et al., 2000), RGC axon terminations in the SC become broader (Rossi et al., 2001; McLaughlin et al., 2003), indicating a role of patterned activity in SC map formation. Consistent with the anatomical results, functional studies have shown that the SC maps in the $\beta 2 \mathrm{KO}$ are more diffuse (Cang et al., 2005b; Mrsic-Flogel et al., 2005), and SC neurons have larger-than-normal receptive fields (Chandrasekaran et al., 2005). Interestingly, using an episodic imaging method (Mrsic-Flogel et al., 2005) also reported that the azimuth map is expanded in the anterior SC and compressed in the posterior SC, suggesting an involvement of structured activity in forming the initial course map in addition to its role in map refinement.

A computational model that includes graded guidance cues, axon-axon competition, and activity-dependent contribution can simulate the formation of precise retinotopic maps and many phenotypes seen in ephrin-A mutants (Tsigankov and Koulakov, 2006). Such a model also predicts that, in the absence of guidance cues, structured activity can form patches of smooth maps by clustering local neighboring neurons in the SC (Tsigankov and Koulakov, 2006) (Fig. 5). Here, we imaged the overall structure of SC maps in the ephrin-A TKOs and found that their azimuth maps are indeed discontinuous with patches of smooth maps. Importantly, the ephrin-A2A5- $\beta 2$ combination KOs do not contain any clusters of local maps in their SC, suggesting that the clusters in ephrin-A TKOs are formed by $\beta 2$-dependent retinal waves, in support of the above model.

The above discussions interpret the mapping defects in the $\beta 2$ KOs as resulting from the disruption of retinal activity, but the exact activity patterns in the intact retina and SC during development remain unknown. One in vitro study showed that in the $\beta 2 \mathrm{KOs}$ some ganglion cells become silent, and the others have uncorrelated but increased firing (McLaughlin et al., 2003). However, it was recently observed that correlated activity still exist in these mice in vitro at more physiological conditions (Ballesteros et al., 2007) (D. A. Feldheim, unpublished data), although the precise structures of the correlated activity are altered. Therefore, future studies are critically needed to reveal the patterns of retinal activity in vivo in WT and $\beta 2$ $\mathrm{KOs}$, and to determine what changes in the activity structures account for the mapping defect seen in the SC.

\section{Comparison of collicular maps with cortical maps}

Retinotopic representation of the visual space is also preserved through the dorsal lateral geniculate nucleus to the V1. We have previously studied functional retinotopic maps in $\mathrm{V} 1$ and geniculocortical projections in ephrin-A2/A3/A5 triple KOs (Cang et al., 2005a), nAChR- $\beta 2$ KOs (Cang et al., 2005b), and ephrin-A2A5- $\beta 2$ combination KOs (Cang et al., 2008). Orderly geniculocortical projections are disrupted in ephrin-A TKOs (Cang et al., 2005a) and become diffuse in $\beta 2 \mathrm{KOs}$ (Cang et al., 2005b), similar to the phenotypes seen in their SC (McLaughlin et al., 2003; Pfeiffenberger et al., 2006). In addition, deficiency in both ephrin-As and structured activity results in near complete abolition of topography along the NT axis of both the SC and V1, while leaving their DV maps relatively normal (Cang et al., 2008) (Fig. 6).

Although both ephrin-A- and activity-dependent mechanisms are used to map visual projections, their relative contributions to form functional maps differ in SC and V1. First, although ephrin-A TKOs have large anatomical defects in their geniculocortical projections, the functional maps in V1 are not patchy as in SC, but blurry with normal global polarity (Cang et al., 2005a). This suggests that activity-dependent mechanisms may be able to silence the synapses of aberrant axons in the cortex, more so than in SC. We also found that the functional maps in $\beta 2$ KOs are more diffuse in V1 than in SC (Cang et al., 2005b), suggesting that activity-dependent mechanisms contribute more to map formation in cortex than in SC. It is certainly conceivable that geniculocortical synapses are more plastic than retinocollicular synapses. In addition, the greater contribution of structured activity in V1 could be attributable to longer lateral interactions; as in the modeling study, a global topography can be recovered in the absence of ephrin-As by increasing the range of activity-dependent interactions (Tsigankov and Koulakov, 2006). Although the exact extent of intracortical or intracollicular interactions during development remains unknown, it has been shown that there are more convergence for projections to cortex than to SC [approximately five inputs in the SC (Chandrasekaran et al., 2007), and probably 10 times more in cortex (Alonso et al., 2001; Bruno and Sakmann, 2006)]. Further modeling studies incorporating the difference in convergence could reveal whether it influences the relative contribution of activity-dependent mechanisms in map formation.

The SC maps were obtained in the absence of visual cortex. This is necessary to expose the SC for imaging, and it also allows us to selectively study the function of retinocollicular projections. Although the SC maps are imaged in the absence of inputs from V1, electrophysiological studies demonstrated that ablating or silencing visual cortex does not change receptive field positions of the SC neurons (Schiller et al., 1974; Dräger and Hubel, 1976). In other words, retinocollicular and corticocollicular inputs are in register in the SC of WT animals. It is thus interesting to examine whether this is still the case in mutant mice where retinotopic maps are differently disrupted in the SC and V1, such as in the ephrin-A TKOs. Future anatomical and physiological experiments are needed to address this question.

In conclusion, we have used optical imaging of intrinsic signals to examine functional retinotopic maps in the SC of mice deficient in ephrin-As and normally structured retinal activity. Our experiments demonstrate that the aberrant retinal projections form functional maps in these mice. By studying the overall structure of SC maps, we have revealed the contributions of ephrin-As and activity-dependent mechanisms in retinocollicular map formation. We also demonstrated the usefulness of our imaging method, which allows for rapid delineation of detailed retinotopic maps in the SC and visual cortex. Combined with mouse genetics, this imaging method is a powerful technique in the study of visual system development.

\section{References}

Alonso JM, Usrey WM, Reid RC (2001) Rules of connectivity between geniculate cells and simple cells in cat primary visual cortex. J Neurosci 21:4002-4015.

Ballesteros JM, Sun C, Goloshchapov AV, Cheng H, Chalupa LM (2007) Developing $\mathrm{nAChR} \beta 2-/-$ mice manifest retinal waves of action poten- 
tials as well as altered retinogeniculate projection patterns. Soc Neurosci Abstr 33:346.21.

Bansal A, Singer JH, Hwang BJ, Xu W, Beaudet A, Feller MB (2000) Mice lacking specific nicotinic acetylcholine receptor subunits exhibit dramatically altered spontaneous activity patterns and reveal a limited role for retinal waves in forming ON and OFF circuits in the inner retina. J Neurosci 20:7672-7681.

Brown A, Yates PA, Burrola P, Ortuño D, Vaidya A, Jessell TM, Pfaff SL, O'Leary DD, Lemke G (2000) Topographic mapping from the retina to the midbrain is controlled by relative but not absolute levels of EphA receptor signaling. Cell 102:77-88.

Bruno RM, Sakmann B (2006) Cortex is driven by weak but synchronously active thalamocortical synapses. Science 312:1622-1627.

Butts DA, Rokhsar DS (2001) The information content of spontaneous retinal waves. J Neurosci 21:961-973.

Cang J, Kaneko M, Yamada J, Woods G, Stryker MP, Feldheim DA (2005a) Ephrin-as guide the formation of functional maps in the visual cortex. Neuron 48:577-589.

Cang J, Rentería RC, Kaneko M, Liu X, Copenhagen DR, Stryker MP (2005b) Development of precise maps in visual cortex requires patterned spontaneous activity in the retina. Neuron 48:797-809.

Cang J, Niell CM, Liu X, Pfeiffenberger C, Feldheim DA, Stryker MP (2008) Selective disruption of one cartesian axis of cortical maps and receptive fields by deficiency in ephrin-as and structured activity. Neuron 57:511-523.

Chandrasekaran AR, Plas DT, Gonzalez E, Crair MC (2005) Evidence for an instructive role of retinal activity in retinotopic map refinement in the superior colliculus of the mouse. J Neurosci 25:6929-6938.

Chandrasekaran AR, Shah RD, Crair MC (2007) Developmental homeostasis of mouse retinocollicular synapses. J Neurosci 27:1746-1755.

Cheng HJ, Flanagan JG (1994) Identification and cloning of ELF-1, a developmentally expressed ligand for the Mek4 and Sek receptor tyrosine kinases. Cell 79:157-168.

Cheng HJ, Nakamoto M, Bergemann AD, Flanagan JG (1995) Complementary gradients in expression and binding of ELF-1 and Mek4 in development of the topographic retinotectal projection map. Cell 82:371-381.

Cline H (2003) Sperry and Hebb: oil and vinegar? Trends Neurosci 26:655-661.

Cutforth T, Moring L, Mendelsohn M, Nemes A, Shah NM, Kim MM, Frisén J, Axel R (2003) Axonal ephrin-As and odorant receptors: coordinate determination of the olfactory sensory map. Cell 114:311-322.

Debski EA, Cline HT (2002) Activity-dependent mapping in the retinotectal projection. Curr Opin Neurobiol 12:93-99.

Demas J, Eglen SJ, Wong RO (2003) Developmental loss of synchronous spontaneous activity in the mouse retina is independent of visual experience. J Neurosci 23:2851-2860.

Dräger UC, Hubel DH (1975) Responses to visual stimulation and relationship between visual, auditory, and somatosensory inputs in mouse superior colliculus. J Neurophysiol 38:690-713.

Dräger UC, Hubel DH (1976) Topography of visual and somatosensory projections to mouse superior colliculus. J Neurophysiol 39:91-101.

Drescher U, Kremoser C, Handwerker C, Löschinger J, Noda M, Bonhoeffer F (1995) In vitro guidance of retinal ganglion cell axons by RAGS, a 25 $\mathrm{kDa}$ tectal protein related to ligands for Eph receptor tyrosine kinases. Cell 82:359-370.

Feldheim DA, Kim YI, Bergemann AD, Frisén J, Barbacid M, Flanagan JG (2000) Genetic analysis of ephrin-A2 and ephrin-A5 shows their requirement in multiple aspects of retinocollicular mapping. Neuron 25:563-574.

Feldheim DA, Nakamoto M, Osterfield M, Gale NW, DeChiara TM, Rohatgi R, Yancopoulos GD, Flanagan JG (2004) Loss-of-function analysis of EphA receptors in retinotectal mapping. J Neurosci 24:2542-2550.

Flanagan JG (2006) Neural map specification by gradients. Curr Opin Neurobiol 16:59-66.

Flanagan JG, Vanderhaeghen $\mathrm{P}$ (1998) The ephrins and Eph receptors in neural development. Annu Rev Neurosci 21:309-345.

Flenniken AM, Gale NW, Yancopoulos GD, Wilkinson DG (1996) Distinct and overlapping expression patterns of ligands for Eph-related receptor tyrosine kinases during mouse embryogenesis. Dev Biol 179:382-401.

Frisén J, Yates PA, McLaughlin T, Friedman GC, O’Leary DD, Barbacid M (1998) Ephrin-A5 (AL-1/RAGS) is essential for proper retinal axon guidance and topographic mapping in the mammalian visual system. Neuron 20:235-243.

Galli L, Maffei L (1988) Spontaneous impulse activity of rat retinal ganglion cells in prenatal life. Science 242:90-91.
Godement P, Salaün J, Imbert M (1984) Prenatal and postnatal development of retinogeniculate and retinocollicular projections in the mouse. J Comp Neurol 230:552-575.

Hindges R, McLaughlin T, Genoud N, Henkemeyer M, O'Leary DD (2002) EphB forward signaling controls directional branch extension and arborization required for dorsal-ventral retinotopic mapping. Neuron 35:475-487.

Kalatsky VA, Stryker MP (2003) New paradigm for optical imaging: temporally encoded maps of intrinsic signal. Neuron 38:529-545.

Mann F, Ray S, Harris W, Holt C (2002) Topographic mapping in dorsoventral axis of the Xenopus retinotectal system depends on signaling through ephrin-B ligands. Neuron 35:461-473.

Marcus RC, Gale NW, Morrisson ME, Mason CA, Yancopoulos GD (1996) Eph family receptors and their ligands distribute in opposing gradients in the developing mouse retina. Dev Biol 180:786-789.

McLaughlin T, O'Leary DD (2005) Molecular gradients and development of retinotopic maps. Annu Rev Neurosci 28:327-355.

McLaughlin T, Torborg CL, Feller MB, O'Leary DD (2003) Retinotopic map refinement requires spontaneous retinal waves during a brief critical period of development. Neuron 40:1147-1160.

Meister M, Wong RO, Baylor DA, Shatz CJ (1991) Synchronous bursts of action potentials in ganglion cells of the developing mammalian retina. Science 252:939-943.

Montague PR, Gally JA, Edelman GM (1991) Spatial signaling in the development and function of neural connections. Cereb Cortex 1:199-220.

Mrsic-Flogel TD, Hofer SB, Creutzfeldt C, Cloëz-Tayarani I, Changeux JP, Bonhoeffer T, Hübener M (2005) Altered map of visual space in the superior colliculus of mice lacking early retinal waves. J Neurosci 25:6921-6928.

Pfeiffenberger C, Yamada J, Feldheim DA (2006) Ephrin-As and patterned retinal activity act together in the development of topographic maps in the primary visual system. J Neurosci 26:12873-12884.

Rashid T, Upton AL, Blentic A, Ciossek T, Knoll B, Thompson ID, Drescher U (2005) Opposing gradients of ephrin-As and EphA7 in the superior colliculus are essential for topographic mapping in the mammalian visual system. Neuron 47:57-69.

Rossi FM, Pizzorusso T, Porciatti V, Marubio LM, Maffei L, Changeux JP (2001) Requirement of the nicotinic acetylcholine receptor beta 2 subunit for the anatomical and functional development of the visual system. Proc Natl Acad Sci U S A 98:6453-6458.

Schiller PH, Stryker M, Cynader M, Berman N (1974) Response characteristics of single cells in the monkey superior colliculus following ablation or cooling of visual cortex. J Neurophysiol 37:181-194.

Schuett S, Bonhoeffer T, Hübener M (2002) Mapping retinotopic structure in mouse visual cortex with optical imaging. J Neurosci 22:6549-6559.

Simon DK, O'Leary DD (1992) Development of topographic order in the mammalian retinocollicular projection. J Neurosci 12:1212-1232.

Sperry RW (1963) Chemoaffinity in the orderly growth of nerve fiber patterns and connections. Proc Natl Acad Sci U S A 50:703-710.

Torborg CL, Feller MB (2005) Spontaneous patterned retinal activity and the refinement of retinal projections. Prog Neurobiol 76:213-235.

Tsigankov DN, Koulakov AA (2006) A unifying model for activity-dependent and activity-independent mechanisms predicts complete structure of topographic maps in ephrin-A deficient mice. J Comput Neurosci 21:101-114.

Warland DK, Huberman AD, Chalupa LM (2006) Dynamics of spontaneous activity in the fetal macaque retina during development of retinogeniculate pathways. J Neurosci 26:5190-5197.

Willshaw DJ, von der Malsburg C (1976) How patterned neural connections can be set up by self-organization. Proc R Soc Lond B Biol Sci 194:431-445.

Wong RO (1999) Retinal waves and visual system development. Annu Rev Neurosci 22:29-47.

Xu W, Orr-Urtreger A, Nigro F, Gelber S, Sutcliffe CB, Armstrong D, Patrick JW, Role LW, Beaudet AL, De Biasi M (1999) Multiorgan autonomic dysfunction in mice lacking the beta2 and the beta4 subunits of neuronal nicotinic acetylcholine receptors. J Neurosci 19:9298-9305.

Yates PA, Holub AD, McLaughlin T, Sejnowski TJ, O’Leary DD (2004) Computational modeling of retinotopic map development to define contributions of EphA-ephrinA gradients, axon-axon interactions, and patterned activity. J Neurobiol 59:95-113.

Zhang JH, Cerretti DP, Yu T, Flanagan JG, Zhou R (1996) Detection of ligands in regions anatomically connected to neurons expressing the Eph receptor Bsk: potential roles in neuron-target interaction. J Neurosci 16: 7182-7192. 